NBER WORKING PAPER SERIES

\begin{abstract}
ASSET PRICING MODEL SPECIPICATION AND
THE TERM STRUCTURE EVIDENCE
\end{abstract}

\author{
Terry A. Marsh
}

Working Paper No. 1612
NATIONAI, BUREAU OF ECONOMIC RESEARCH
1050 Massachusetts Avenue
Cambridge, MA 02138
April 1985

The research reported here is part of the NBER's research program in Financial Markets and Monetary Economics. Any opinions expressed are those of the author and not those of the National Bureau of Economic Research. 


\section{Asset Pricing Model Specification and the Term structure Evidence}

\section{ABS TRACT}

In this paper, a set of tests of models of relative capital asset prices is developed. The tests are used to examine how well the models explain maturity premiums on Government bonds, though they are perfectly general and hence could be applied to stocks or other assets. Allowance is made in the tests for the nonobservability of investors' optimal per capita consumption (or expected marginal utility).

It is found that the returns on Government bonds bear a systematic risk which is better measured by their covariability with aggregate per capita consumption than with the returns on the NYSE stock market index, the latter being the surrogate-wealth portfolio typically used to measure risk in the traditional Sharpe-Lintner-Mossin CAPM.

Terry A. Marsh

Sloan School of Management Massachusetts Institute of Technology 50 Memorial Drive Cambridge, MA 02139

(617) 253-6652 


\section{Introduction}

Fisher (1930) presented a comprehensive analysis of the determinants of interest rates under certainty, but stopped short of any real efforts to extend his results to a world in which the return streams generated by capital assets are uncertain. Such an extension requires a tractable model for defining and pricing the differences across assets with respect to the uncertainty of their returns. Sharpe (1964), Lintner (1965), Mossin (1966), and Elack (1972) all showed that an equilibrium in which investors hold mean-variance efficient portfolios, as they will do if asset returns are normally distributed and/or if their utility functions are ouadratic [Tobin (1958)], implies that a "capital asset pricing model" (CAPM) descrjbes the risk and return characteristics of all assets.

The CAPM, which Merton (1971) showed could be derived for general utility functions if asset returns follow geometric Erownian motion processes in continuous time, is straightforward: assets are priced so that the crosssectional differences in average rates of return which they generate are a linearly increasing function of differences in their "systematic" risk, defined to be the incremental risk that they contribute to an investor's efficient portfolio. If all assets are traded and investors have homogeneous beliefs, it is well known that the efficient portfolio will be the value-weighted portfolio of all assets. Ross (1976) (1977) showed that if asset returns are generated by a linear factor model, then the essence of the CAPM remains intact when it is applied to observed market portfolios which are well diversified, but not necessarily mean-variance efficient. 
Most recent research on asset pricing models has focused on what happens if the probability distribution of asset returns shifts around over time. Merton (1973) showed that when such shifts occur, assets can still be priced, in the spirit of the CAPM, in terms of a set of mutual funds whose composition does not depend upon investor preferences. Unfortunately, identification of the mutual funds has proved to be a major stumbling block for empirical tests of this intertemporal extension of the CAPM. Cox, Ingersoll, Ross (1977) and Brock (1982) showed how an explicit link between asset prices and the production sector might provide such identification. Alternatively, in a model that is consistent with those of Merton, Cox-Inoersoll-Ross, and Rrock, Ereeden (1979) and Crossman and Shiller (1982) derived a "consumption CAPM" (CCAPM) in which each asset's risk premium is proportional to the covariance of its return with per capita aggregate consumption. This CCAPM could potentially retain the real sector-asset price linkage and yet remain empirically tractable.

The objective of this paper is to test how well the CCAPM explains the returns on a cross-section of long-term, default-free, Government bonds--that is, the term structure--and to assess how well this model compares with the earlier stock-market-portfolio-oriented CAPM. The market value of U.S. Government bonds outstanding at the end of 1983 was about a trillion dollars, ${ }^{1}$ and this fact alone might justify the focus here on default-free bond returns. However, the study of bond returns should also be particularly helpful in evaluating models for pricing assets in general. Inflation uncertainty aside, the only reason that payoffs on default-free bonds are risky is because investors' overall levels of wealth and/or opportunities for reinvestment of payoffs covary with the payoffs. By definition, wealth and 
opportunity set changes are not diversifiable, unlike many of the real sector shocks that cause variation in stock returns. Thus real sector shocks should "show up" in bond returns and consumption changes if at all. The returns on bonds over the maturity spectrum analyzed here also span a wide class of security return behavior, including that at the long end which closely resembles stock return behavior. As a result, not much generality is likely to be sacrificed in studying bond returns.

The tests implemented here most closely resemble the time series-cross section tests of the CAPM in Gibbons (1982). However, I test the incremental explanatory power of the CCAPM over the CAPM as well as the fit of both, and to do this I nest the CAPM within the CCAPM. Observation errors in consumption are allowed in the tests. The tests are applied to the asset pricing models stated in real terms, since the inflation component of nominal bond returns is important, whereas it can generally be ignored for stocks. The tests are also applied to rates of return whose expectation is conditional on the one period nominal risk-free rate of interest, though real $r$ isk premiums are otherwise assumed to be constant. As Grossman and Shiller (1982) and others have pointed out, it may be perfectly leoitimate to assume that unconditional expectations and risk premiums are constant, though doino so neglects any additional structure which would exist in the time series of changes in expected returns and risk premiums if those changes could be predicted by variables other than the risk-free rate. Such information would be captured in the tests of Hansen and Singleton (1982) (1983) and Gibbons and Ferson (1985), though at the additional expense of specification of a conditional returns model which here would tax the relatively short available history of bond return observations. 2 
The results here suggest that the CCAPM can significantly improve upon the CAPM in explaining risk premiums (term premiums) on bonds. Further, the restrictions imposed by the CCAPM across the risk premiums on bonds with different terms to maturity cannot be rejected for all but the shortest maturity bonds. This is interesting because the time series behavior of bond returns at the longer maturities, where the restrictions hold, most closely resembles the time series behavior of common stocks for which these types of asset pricing restrictions have been rejected in the past. In Section 4, I discuss some possible reasons for the difference in results.

In the following section, I define the CCAPM and the CAPM, and state the hypotheses about them which are to be tested. The testable restrictions implied by the hypotheses are formulated in Section 2.2 , and the structure which accounts for errors in measuring consumption is introduced in Section 2.3. The tests are briefly discussed in Section 2.4. Results are presented in Section 3. 
2. Tests for Asset Pricing Model Specification

2.1 Definition of the Models

The CCAPM is:

$$
E\left(R_{j t}\right)-R_{F t}-E\left(R_{j t, \pi_{t}}\right)=B_{j}^{C}\left[E\left(R_{M t}\right)-R_{F t}-E\left(R_{M t}, \pi_{t}\right)\right]
$$

where:

$\mathrm{R}_{\mathrm{Ft}}$ is the nominal risk-free rate of interest over period $t$ which is predetermined at the beginning of period $t$;

$R_{j t}$ is the nominal rate of return on asset $j$ over period $t$. The rate of return on asset $j$ over period $t$ equals the sum of the change in its price over the period and any cash income, such as dividends on stocks or coupons on bonds, which is received over the period, as a ratio of its beginning of period price;

$\pi_{t}$ is the period $t$ inflation rate; $R_{\text {Mt }}$ is the nominal rate of return on a market portfolio of stocks over
period $t ;$

$$
B_{j}^{C}=\frac{\operatorname{cov}\left(R_{j t}-\pi_{t}, \frac{\Delta C_{t}^{*}}{C_{t-1}^{*}}\right)-\operatorname{cov}\left(R_{F t}-\pi_{t}, \frac{\Delta C_{t}^{*}}{C_{t-1}^{*}}\right)}{\operatorname{cov}\left(R_{M t}-\pi t, \frac{\Delta C_{t}^{*}}{C_{t-1}^{*}}\right)-\operatorname{cov}\left(R_{F t}-\pi_{t}, \frac{\Delta C_{t}^{*}}{C_{t-1}^{*}}\right)}
$$

$\Delta C_{t}^{*} / C_{t-1}^{*}$ is the percentage change in optimal per capita consumption flow from that over period $t-1$ to that over period $t$, where "optimal" means that it satisfies the envelope condition of the representative consumer-investor's dynamic optimization problem which is discussed in Merton (1971). Initialiy, consumption changes are assumed to be observable without error.

The CCAPM in (1) states that the period-t risk premium on any asset j is proportional to that on any other asset $M$, where the factor of proportionality is the "consumption risk" coefficient ${ }^{C}{ }_{j}$ defined in (2). Although the risk premiums on assets $j$ and $M$ are defined in terms of 
nominal rates of return in (1), they can be interpreted as "Ieal" premiums. For example, the risk premium on the left-hand side of (1) can be re-expressed as the expectation of the difference between the real rate of return on asset $j$ and the (uncertain) real rate of return on the nominally risk-free asset:

$$
E\left(R_{j t}-R_{F t}-E\left(R_{j t} \pi_{t}\right)=E\left[\left(R_{j t}-\pi_{t}\right)-\left(R_{F t}-\pi_{t}\right)\right]\right.
$$

where the nominal risk-free rate $R_{F t}$ is predetermined at the beginning of period t. Since the risk premiums on assets $j$ and $M$ in (1) are real, it should not be surprising that the consumption risk coefficient $B_{j}^{C}$ in (2) involves the covariation of the real risk premium on assets $j$ and $M$ with real consumption.

As Breeden (1979) discusses in detail, the consumption risk measure $B_{j}^{C}$ is sufficient to explain equilibrium risk premiums on assets because per capita consumption changes reflect changes in investors' maroinal utilities occasioned by movements in wealth and investment opportunities. The cross-product $E\left(R_{j t} t_{t}\right)$ in (1) accounts for asset j's "systematic nominal risk," i.e., inflation uncertainty ${ }^{3}-$ if, on average, asset $j$ 's dollar return is high in periods in which inflation is high, then that asset must provide a higher expected nominal rate of return to yield a given real risk premium because the dollar returns will buy fewer consumption goods when prices have risen.

The Sharpe-Lintner-Mossin CAPM can be obtained by replacing the per capita consumption change variable in the expression for $B_{j}^{C}$ by the rate of return on a surrogate for the market portfolio of assets, typicaliy a stock market index. The real CAPM "market beta" which replaces $B_{j}^{C}$ is:

$$
B_{j}^{M}=\frac{\operatorname{cov}\left[\left(R_{j t}-\pi_{t}\right)-\left(R_{F t}-\pi_{t}\right),\left(R_{M t}-\pi_{t}\right)\right]}{\operatorname{cov}\left[\left(R_{M t}-\pi_{t}\right)-\left(R_{F t}-\pi_{t}\right),\left(R_{M t}-\pi_{t}\right)\right]}
$$


The hypotheses to be tested here are:

$H_{0}(1)$ : Does the CCAPM, as given in (1), hold for the pricing of defaultfree bonds?

$H_{0}(2)$ : Does the CCAPM add any explanatory power beyond the CAPM where the latter is given by (1) with the consumption beta $B_{j}{ }_{j}$ replaced by the market beta $B_{j}^{M}$ ?

$H_{0}(3)$ : Do per capita consumption changes reflect changes in investors' marginal utilities better than the returns on observed market portfolios such as stock indices if the pricing of honds is not constrained to conform to the CCAPM?

$H_{0}(4)$ : Does the CAPM hold?

To test these hypotheses, I formulate them as restrictions on the distribution of asset returns and consumption changes. That is, I show that there is a "market model" [statistical model] of returns and consumption changes on which the CCAPM imposes a testable structure, just as the traditional CAPM imposes restrictions on multivariate asset return distributions [e.g., Black, Jensen and Scholes (1972), Fama and Macbeth (1973), and Gibbons (1982)].

\subsection{Test Procedure}

The basic market model on which the CCAPM imposes restrictions is the simple two-eouation system:

$$
\begin{aligned}
& \left(R_{j t}{ }^{-\pi} t\right)-B_{12 j}^{C}\left(R_{M t^{-\pi} t}\right)-B_{13 j}^{C}\left(R_{F t}-\pi t\right) \quad=u_{j t}
\end{aligned}
$$

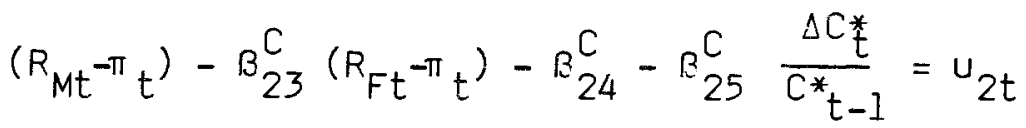


where the disturbance $\underline{u}_{t}^{\prime}=\left[u_{j t}, u_{2 t}\right]$ is independently and identically distributed through time with $E \underline{u}=0$ and $E \underline{u}^{\prime}=\Sigma$, where $\Sigma$ is a positive definite symmetric matrix; $E\left(\underline{u}_{t} \mid \Delta C{ }_{t} / C^{*}{ }_{t-1}\right)=0$; and $B_{12 \mathrm{j}}^{C}, \ldots, B_{25}^{C}$ are constant coefficients.

If the coefficient restrictions $B_{13 j}^{C}=\left(1-R_{12 j}^{C}\right)$ and $B_{23}^{C}=1$ are applied in (5) and (6), we obtain:

$$
\begin{aligned}
& {\left[\left(R_{j t} t_{t}\right)-\left(R_{F t}{ }^{-\pi} t\right)\right]-B_{12 j}^{C}\left[\left(R_{M t}-\pi_{t}\right)-\left(R_{F t}{ }^{-\pi} t\right)\right]} \\
& =u_{j t} \\
& {\left[\left(R_{M t}-\pi_{t}\right)-\left(R_{F E^{-\pi} t}\right)\right]-B_{24}^{C}-B_{25}^{C} \frac{\Delta C_{t}^{*}}{C_{t-1}^{*}}=u_{2 t}}
\end{aligned}
$$

The reduced form of ( 7$)$ and ( 8 ) is:

$$
\begin{aligned}
& {\left[\left(R_{j t}-\pi_{t}\right)-\left(R_{F t}-\pi_{t}\right)\right]-\Pi_{1}-\pi_{2} \frac{\Delta C_{t}^{*}}{C_{t-1}^{*}}=v_{1 t}} \\
& {\left[\left(R_{M t}-\pi_{t}\right)-\left(R_{F t}-\pi_{t}\right)\right]-\Pi_{3}-\pi_{4} \frac{\Delta C_{t}^{*}}{C_{t-1}^{*}}=v_{2 t}}
\end{aligned}
$$

where the structural coefficient $R Q_{12 j}$ is just identified:

$$
\begin{aligned}
\pi_{2} & =B_{12 j}^{C} B_{23}^{C} \\
\pi_{4} & =B_{23}^{C} \\
\Rightarrow \quad B_{12 j}^{C} & =\frac{\pi_{2}}{\pi_{4}}=\frac{\operatorname{cov}\left[\left(R_{j t}{ }^{-\pi} t\right)-\left(R_{F t}-\pi t\right), \frac{\Delta C_{t}^{*}}{C_{t-1}^{*}}\right]}{\operatorname{cov}\left[\left(R_{M t}-\pi_{t}\right)-\left(R_{F t}-\pi_{t}\right), \frac{\Delta C_{t}^{*}}{C_{t-1}^{*}}\right]} \\
& =R_{j}^{C}
\end{aligned}
$$


Also, from (5):

$$
E\left[\left(R_{j t} t_{t}\right)-\left(R_{F t}-\pi t\right)\right]=R_{12 j}^{C} E\left[\left(R_{M t}-\pi t\right)-\left(R_{F t}-\pi t\right)\right]+E\left[u_{j t} \mid R_{F t}\right]
$$

Since $R_{F t}$ is predetermined, $E\left[u_{j t} \mid R_{F t}\right]=0$, and it is straightforward to verify that, with $B_{12 j}^{C}=R_{j}^{C},(13)$ is equivalent to (1). Thus $H_{0}(1)$ can be expressed as:

$$
H_{0}(1): \quad\left(1-B_{12 j}^{C}\right)=B_{13 j}^{C} ; \quad B_{23}^{C}=1 \text { for all assets } j
$$

with the composite alternative:

$$
H_{A}(1): \quad\left(1-B_{12 j}^{C}\right) \neq B_{13 j}^{C} ; \quad B_{23}^{C} \neq 1 .
$$

The test of $\mathrm{H}_{0}(2)$ follows immediately from the two-eouation system (5) and (6). Since $\mathrm{F}_{\mathrm{Ft}}$ is predetermined, that two-eauation system is recursive if $\operatorname{cov}\left(u_{j t}, u_{2 t}\right)=0$. If it is recursive, $B_{12 j}^{C}$ will be determined by equation (5) alone. In that case, it will eaul the CAPM beta as given in (4). Hence, a test of whether the CCAPM reduces to the CAPM can be expressec as:

$$
\begin{aligned}
& H_{0}(2): \quad \operatorname{cov}\left(u_{j t}, u_{2 t}\right)=0 \quad, B_{13 j}^{C}=\left(1-B_{12 j}^{C}\right) ; \quad B_{23}=1 \\
& H_{A}(2): \quad \operatorname{cov}\left(u_{j t}, U_{2 t}\right) \neq 0 \quad, \quad B_{13 j}^{C}=\left(1-B_{12 j}^{C}\right) ; \quad B_{23}=1
\end{aligned}
$$

The counterpart of $\mathrm{H}_{0}(2)$ is the third hypothesis $\mathrm{H}_{0}(3)$ that the two-equation system (5) and (6) reduces to the single equation "system" (5), although the restrictions imposed on the structural coefficients of (5) and (6) by the CCAPM and CAPM might not hold: 


$$
\begin{aligned}
& H_{0}(3): \quad \operatorname{cov}\left(u_{j t}, u_{2 t}\right)=0, B_{12 j}^{C}, B_{13 j}^{C}, B_{23}^{C} \text { unrestricted } \\
& H_{A}(3): \quad \operatorname{cov}\left(u_{j t}, u_{2 t}\right) \neq 0, B_{12 j}^{C}, B_{13 j}^{C}, B_{23}^{C} \text { unrestricted }
\end{aligned}
$$

The final hypothesis considered here--that the CAPM holds--can be expressed as:

$$
\begin{aligned}
& H_{0}(4): \quad B_{13 j}^{C}=\left(1-B_{12 j}^{C}\right), \quad \operatorname{cov}\left(u_{j t}, u_{2 t}\right)=0 \\
& H_{A}(5): \quad B_{13 j}^{C} \neq\left(1-B_{12 j}^{C}\right), \operatorname{cov}\left(u_{j t}, u_{2 t}\right)=0
\end{aligned}
$$

\subsection{Unobserved Marginal Utility or Per Capita Consumption}

So far, it has been assumed that optimal per capita consumption changes which, in the CCAPM, are a measure of changes in the representative investor's marginal utility, are observable. But if per capita consumption is itself measured with error in the available data, measured consumption might more appropriately be regarded as an indicator, along with other variables, of a latent variable directly quantifying the representative investor's marginal utility. ${ }^{4}$ Defining $\xi_{t}$ to be this latent variable, the model used to take such measurement errors into account in the tests here is:

$$
\begin{aligned}
& x_{1 t}=\lambda_{1} \xi_{t}+\varepsilon_{1 t} \\
& \cdot \\
& x_{k t}=\lambda_{k} \xi_{t}+\varepsilon_{k t}
\end{aligned}
$$

where $\xi_{t} \equiv \Delta C^{*} t^{/ C^{*}} t-1$ in all of the previous discussion. Any one of the $k$ indicator variable $x$ 's might be observed per capita 
consumption; the properties of $\underline{\varepsilon}^{\prime}=\left[\varepsilon_{1}, \ldots, \varepsilon_{k}\right]$ will be discussed below.

Note that simply plugging any of the $X$ 's in (14) into (5) and (6) as an instrument for $\xi_{t}$ would not induce an errors-in-variables inconsistency in $B_{12 j}^{C}$, since the unobservable variable does not appear in (5). The measurement error would cause inconsistent estimates of $B_{24}^{C}, B_{25}^{C}$. Given the measurement error model (14), the estimates of $B_{12 j}$ would also be inefficient, as would the tests which are based on the covariance matrix of disturbances in (5) and (6).

Adding specification (14) to (5) and (6) and generalizing the latter to include a cross-section of assets $j=1, \ldots, N$, gives:

$$
\begin{aligned}
& R_{\text {at }}^{1} \quad-B_{12}^{1} R_{\text {Mat }} \quad-B_{13}^{1} R_{F t} \\
& =u_{1 t}^{1} \\
& R_{\text {at }}^{2}-B_{12}^{2} R_{\text {Mat }}-B_{13}^{2} R_{F t} \\
& \begin{array}{ccc}
\vdots & \vdots & \vdots \\
R_{\text {at }}^{N} & -B_{12}^{N} R_{\text {Mat }} & -B_{13}^{N} R_{F t}
\end{array} \\
& =u_{1 t}^{2} \\
& R_{\text {Mat }}-B_{23} R_{F t} \\
& -B_{21}-B_{25} \xi_{t} \\
& =u_{2 t} \\
& x_{1 t} \\
& -\lambda_{1} \xi_{t} \\
& =\varepsilon_{1 t} \\
& \vdots \\
& x_{k t} \\
& -\lambda_{k} \xi_{t} \\
& =\varepsilon_{k t}
\end{aligned}
$$

where: $R_{\text {at }}^{j} \equiv\left(R_{j t}-\pi_{t}\right), \quad R_{\text {Mat }} \equiv\left(R_{M t}-\pi_{t}\right), \quad B_{12}^{j} \equiv R_{12 j}^{C}, \quad R_{13}^{j} \equiv R_{13 j}^{C}$, and the $C$ superscripts are dropped from $B_{23}, B_{24}, B_{25}$.

The linear structure (14) is a special version of the general multiple indicator, multiple cause (MIMIC) model, discussed by Zellner (1970), 
Coldberger (1972a, 1972b) and Aigner (1978). If the elements of $\underline{\varepsilon}_{t}$ were mutually independent, (14) would be, in essence, a confirmatory factor analysis model, with $\left[\lambda_{1}, \ldots, \lambda_{k}\right]$ interpretable as factor loadings. Elements of $\underline{\varepsilon}$ may be correlated here however, e.g., in the multivariate marginal distribution of $\left(X_{1}, X_{2}\right), \operatorname{cov}\left(X_{1}, X_{2}\right)=Y_{2} Y_{3} \sigma_{\xi \xi}+\operatorname{cov}\left(\varepsilon_{1}, \varepsilon_{2}\right)$, which is more general than if (14)were specified as a factor model. It may also be verified that (15) will not be identified without a normalization on the $\underline{\lambda}$ coefficients or on the variance of an element of $\underline{\varepsilon}$. Here, we set $\lambda_{I}$ $\equiv 1$.

Five indicator variables $x_{j}, j=1, \ldots, 5$, are used in the tests here. They are: (i) percentage changes in seasonally adjusted retail sales of nondurable consumer goods; (ii) percentage changes in industrial production of nondurable consumer goods; (iii) the average realized real rate of interest on one-month T-bills over the past twelve months; (iv) the growth rate in the monetary base over the past twelve months; and ( $v$ ) percentage changes in an interpolated monthly series of changes in quarterly per capita consumption estimates reported in the Survey of Current Business. The retail sales and industrial production variables seem intuitively reasonable as potential measures of growth rates in per capita consumption expenditures and, with standard caveats, per capita consumption sevices and investor marginal utility. Also, their use can be rigorously justified in stylized production economies such as those considered by Cox-Ingersoll-Ross (1977) and Brock (1982). Historical real interest rates are used as an indicator of marginal utility changes because movements in real interest rates potentially reflect (ergodic) movements in marginal product [see, for example, Merton's (1973) discussion]. Twelve month moving averages of realized real rates are crude estimates of the ex ante real rate which don't require seasonal adjustment. 
The growth rate in the monetary base is used in an attempt to capture any nonneutral impact of money shocks. Finally, inclusion of the consumption series is directly consistent with the spirit of the CCAPM. In the absence of a comprehensive theoretical equilibrium model, the choice of these variables is admittedly ad hoc (though I can report that these were the only variables considered.').

In the MIMIC model framework, these five variables are treated as indicators of the true well-offness variable rather than as causes of "well offness." While the variables, as either indicators or causes, ${ }^{6}$ could be regarded as instruments for $\xi_{t}$ or $\Delta C^{*}{ }_{t-1} / C^{*}{ }_{t}$, their interpretation here as indicators seems more in line with the notion that $\xi_{t}$ or $\Delta C^{*}{ }_{t-1} C^{*} t$ is inherently unobservable than with the notion that it is directly observable, albeit with error. This interpretation is also consistent with the specification that these $x_{j}, j=1, \ldots, 5$ are, at most, jointly stochastic and channeled through a common unobserved variable $\xi t^{*}$

In the tests below, the vector $\underline{u}^{\prime}=\left[u_{1}^{1}, \ldots, u_{1}^{N}, u_{2}\right]$ is assumed to be orthogonal to $\underline{\varepsilon}$. This assumption, which is an identifying one and hence nontestable, states that any unanticipated returns on the chosen proxy market portfolio which cannot be attributed to changes in the representative investor's marginal utility must be orthogonal to errors in using the indicator variables just discussed to measure those marginal utility changes. As for the choice of the indicator variables themselves, there is no guarantee that this orthogonality assumption is immutable truth. However, the a priori arguments which can be cited in its defense are just as plausible as those which can be cited against it, and I adopt it in the same spirit in which most 
reasonable specifications are adopted--as provisionally true, subject to diagnostic checks.

As pointed out by Hausman (1977), if $\left(\xi, R_{F}, x_{2}, x_{3}, x_{4}, x_{5}\right)$ follow a multivariate distribution for which the following regression function holds:

$$
\underline{\xi}=\underline{z \alpha}+\underline{v}
$$

where $z \equiv\left[\underline{1}_{1}, \underline{x}_{2}, \underline{x}_{3}, x_{4}, x_{5}, \underline{R}_{F}\right]$ and $v \underline{1} z$, then (16) can be substituted into (15) to obtain:

$$
\begin{aligned}
& R_{\text {at }}^{I}-B_{12}^{1} R_{\text {Mat }}-R_{13}^{1} R_{F t} \quad=U_{1 t}^{l} \\
& \vdots \\
& R_{\text {at }}^{N}-B_{12}^{N} R_{\text {Mat }}-B_{13^{R} F t}^{N} \quad=u_{2 t}^{N} \\
& R_{\text {Mat }}-B_{23} R_{F t}-B_{21}-\underline{Z}_{t} B_{25} \underline{\alpha}=u_{2 t}+B_{25} v_{t} \\
& \begin{array}{cccc}
x_{1 t} & -z_{t} \underline{\alpha} & =v_{t} & +\varepsilon_{1 t} \\
\vdots & \vdots & \vdots & \vdots
\end{array}
\end{aligned}
$$

The restriction that $\operatorname{cov}\left(u_{1}^{j}, u_{2}\right)=0$ for bonds of each maturity $j$, which is implied by the null hypothes is $H_{0}(2)$ that the CCAPM does not significantly improve upon the traditional CAPM, can be tested by using the procedure in Hausman (1978). He proposes a test of exogeneity of $R_{\text {Mat }}$ in (17) in which the OLS estimator of $B_{12}^{j}$, which is consistent and efficient under the null hypothesis $\operatorname{cov}\left(u_{1}^{j}, u_{2}\right)=0$ but inconsistent under the alternative $\operatorname{cov}\left(u_{1}^{j}, u_{2}\right) \neq 0$, is compared with an IV estimator which is consistent under both the null and the alternative but efficient only under the former. The formulation of the Hausman test used here involves ols applied to the following transformation of the security return equations in (17): 


$$
R_{\text {at }}^{j}=B_{12}^{j} \hat{R}_{\text {Mat }}+B_{13}^{j} R_{F t}+\phi^{j}{ }_{t}+u_{I t}^{j}
$$

where: $v_{t} \equiv R_{\text {Mat }}-\hat{R}_{\text {Mat }}$, and $\hat{R}_{\text {Mat }}$ is the instrumental variable estimator obtained from the remainder of (17) with $B_{23}=1$. The standard $F$ test for $\phi=0$ is asymptotically equivalent to the conventional Iikelihood ratio, LM and Wald procedures for testing whether $\operatorname{cov}\left(u_{1}^{j}, u_{2}\right)=0 .^{7}$

Given the assumptions on $\underline{u}$ and $\underline{\varepsilon}$, (17) contains restrictions on the disturbance matrix and on the slope coefficients. Thus, al though a full instrumental variable method (e.g., 3SLS) will be consistent, it will not be fully efficient [Rothenberg and Leenders (1964)]. Fully efficient FIML estimates and tests are obtained for (15) with the program MOMENTS. ${ }^{8}$ In the FIML case, a likelihood ratio test of the asset pricing hypotheses is performed.

\subsection{Discussion of the Tests}

The tests just described pertain to the CCAPM (1) which states that the ratio of risk premiums on any two assets $[j$ and $M$ in ( 1$)]$ is proportional to the ratio of the covariabilities of their respective returns with consumption changes. Breeden (1979) originally motivated this model with the argument that since investors make consumption decisions simultaneously with portfolio decisions, the former potentially reflect the intertemporal tradeoffs which determine investors' asset demands and, given exogenous asset supplies, asset prices. Eecause ( 1 ) is a cross-sectional model of relative risk premiums on assets, it contains no explicit utility parameters. 
Hansen and Singleton (1982)(1983) have suggested that attention need not be restricted to relative asset prices. Instead of "substituting out" the utility specification, they retain and use it to study the relation between the risk premium on any single asset and expected movements in consumption. In their analysis, asset risk premiums and the expectation of consumption movements are conditioned on any available information which is assumed relevant to investors. Here, by contrast, only the predetermined risk-free rate and historical inflation rates are used to condition expectations.

At the risk of belaboring the obvious, neither the focus here on relative risk premiums, nor the Hansen and Singleton analysis, is strictly cominant. If the utility specification is correct in the Hansen and Singleton approach, if their model of conditional expectations is correct, and if there are no observation errors in consumption (or at least only particular kinds), then their approach potentially provides information about primitive utility parameters and about the linkage between changes in the absolute level of expected asset returns and expected changes in "real sector" variables. On the other hand, these conditions may fail and yet the CCAPM may still perform acceptably well as a model of relative asset prices in which risk premiums that are unconditional on particular information sets are constant.

It seems unlikely that armchair reasoning will shed much light on the relative merits of the approaches. Limited experience in estimating variations in ex ante risk premiums on surrogate weal th portfolios [e.g., Merton (1980)], suggests that formulating and estimating a model of variations in conditionally expected consumption changes--a model which is not required in (1)--is a nontrivial exercise. This is particularly true 
relative to the likely extent of variation in real premiums on bonds. Also, as was shown by Bhattacharya (1979) using analysis similar to Rubinstein (1976), in continuous time the CCAPM can be obtained for any well-behaved utility function. It is easy to draw the conclusion from this that, if the time interval is "short," asset price movements themselves reveal little about risk aversion parameters. 9

On the other hand, period-by-period movements in risk premiums which cannot be predicted by movements in the predetermined risk-free rate but can be predicted from other information will not be taken into account in the tests here. This does not, of course, invalidate them so long as the unconditional expectation of these partly predictable movements and their covariability with consumption changes remain constant over the test period. 
3. Data and Results

The time series-cross section of bond returns used to fit (15) and (17) is taken from the Center for Research in Security Prices (CRSP) Government Bond Returns File. Since a time series of monthly returns across the maturity spectrum cannot be constructed from the returns on single bonds, a cross-section of portfolios composed of bonds with maturities which fall within given ranges has been constructed. ${ }^{10}$ six portfolios with the following ranges are used in the tests reported here:

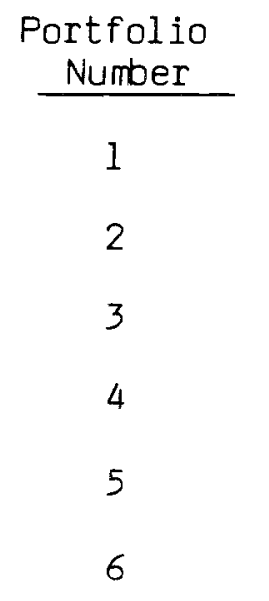

Maturity

$$
0 \quad-6 \text { months }
$$$$
6 \text { months - } 1 \text { year }
$$$$
1 \text { year }-2 \text { years }
$$$$
2 \text { years }-3 \text { years }
$$$$
3 \text { years - } 5 \text { years }
$$$$
5 \text { years }
$$

Average Maturity $\underline{1958 / 2-1978 / 12}$

2.70 months

8.74 months

1.47 years

2.48 years

3.41 years

8.74 years

As mentioned earlier, five indicator variables--referred to as $\underline{x}_{t}$-are used in fitting (15). The variables are: percentage changes in seasonally adjusted real retail sales of nondurable consumer goods, percentage changes in industrial production of nondurable consumer goods, the average realized real rate of return on one-month T-Eills over the past twelve months, the growth rate in the monetary base over the past twelve months, and percentage changes in the interpolated monthly series of quarterly per capita consumption obtained from the MPS Quarterly Econometric 
Model data file. The stock market returns are those for the value-weighted NYSE index, but it has been verified that the results here hold a fortiori if the equally weighted index is used.

A longstanding question in the term structure literature is whether, in equilibrium, investors can expect to earn "term premiums" for holding long term bonds. If, instead of being defined in terms of bond yields-tomaturity across maturities, the term structure is defined as the cross-section of the excess in expected monthly rates of return on long term bonds over the risk-free rate of return on a bond maturing at the end of the month, the CCAPM posits that term premiums--here risk premiums--will be positive only if bond returns covary systematically with changes in per capita consumption. The point estimates for the systematic risk coefficient $B_{12}$ in (15), presented in Tables 1 and 2 and computed using instrumental variables and FIML respectively, suggest that long term bonds are risky, but that their risk does not increase monotonically with maturity. The point estimates increase with maturity up to three years, but decrease with maturity thereafter. This term structure (in holding period returns) would be consistent with the longest term bonds possessing "depression insurance," but given the standard errors of the point estimates [which are not independent across maturities], the hypothesis that premiums are equal beyond a one-year maturity could not be rejected using a Bonferoni test. The point estimates of the risk coefficients are small relative to those usually found in the stock market [e.g., Breeden (1980) reports consumption betas in excess of 2.0 for portfolios of stocks]. 
Test statistics for the four hypotheses concerning asset pricing model specification are presented in Table 3 . The null hypotheses are: $H_{0}(1)--$ The CCAPM holds for pricing default-free bonds; $H_{0}(2)--$ The CCAPM does not add incremental explanatory power to the CAPM; $H_{0}(3)$--Per capita consumption changes do not reflect changes in investors' marginal utilities any better than do the returns on the NYSE value-weighted index even though the pricing of bonds isn't constrained to conform with the CCAPM; $\mathrm{H}_{0}(4)--$ The Sharpe-Lintner-Mossin CAPM holds.

As can be seen from Table 3, the CCAPM and CAPM pricing restrictions are rejected only for the portfolio of bonds with maturities less than six months. Of course, the tests applied to the different maturities are not independent, but when the test is performed simultaneously across maturities using FIML, the restrictions cannot be rejected at conventional significance levels. On the other hand, hypotheses two and three--that consumption-based models of asset pricing do not better reflect investor marginal utility than the NYSE value-weighted market index--are rejected. For the Hausman tests, where a Wald statistic is used for testing the equality of the $B_{12}$ and $\phi_{12}$ coefficients which are given in Tables 1 and $2, H_{0}(2)$ and $H_{0}(3)$ are rejected at the $99.5 \%$ significance level. The FIML test statistic, which is $-2 \ln \lambda$ where $\lambda$ is the usual likelihood ratio value, is beyond the $99.9 \%$ chi-square confidence level. ${ }^{11}$ As might be suspected from the failure to reject $H_{0}(1)$ and $H_{0}(4)$, the conclusion that consumption changes (within the MIMIC model framework here) outperform the NYSE index as a measure of investor marginal utility is insensitive to whether or not the CCAPM restrictions are imposed. 


\section{Summary and Conclusions}

In this paper, tests have been developed for a set of hypotheses concerning specification of the CCAPM and its explanatory power vis-a-vis the traditional CAPM. When the tests were implemented on Government bonds, it was found that for all but those with maturities less than six months, the restrictions on the distribution of asset returns and consumption changes implied by the CCAPM could not be rejected when due allowance was made for the effects of inflation and measurement errors in consumption. The CCAPM also seemed to explain term premiums better than the CAPM.

The result concerning the validity of the CCAPM restrictions contrasts somewhat with Gibbons's (1982) finding that similar restrictions imposed by the Black form of the traditional Sharpe-Lintner-Moss in CAPM could be rejected for common stock returns. The difference may occur for a couple of reasons. First, in the Cibbons tests, the expected rate of return on the zero-beta asset which, in the Black model, replaces the risk-free asset, was assumed to be constant over time. The risk-free rate in the Sharpe-LintnerMoss in model which is incorporated in the tests here is allowed to vary through time. Only the bond expected rates of return conditional on the one-month T-Bill rate must be assumed to be constant. of course, a potential cost of including the variable risk-free rate is that, in the tests here, it is more likely that the CAPM will be rejected in favor of the CCAPM because the risk-free rate is not consistent with the NYSE stock index's being a good surrogate for "true wealth" [Roll (1976)]. Second, the power of the test here may be low; yet one might have expected that the power would be most lacking at the short end of the maturity spectrum where 
the restriction is rejected. Third, there could be other misspecifications that have a more severe impact on the statistical model for longer-term bonds. For example, the variance-covariance matrix of the deviations of returns from their conditional expectations might not be constant, and the misspecification might be more severe at longer maturities.

Clearly, there are many considerations which have necessarily been ignored here, but impinge on the results nonetheless. First, all the tests are asymptotic. Second, tax effects have been ignored in the tests. On this second point, it can be proved [Marsh (1980), Appendix F] that fairly general taxation policies have no effect on the prices of discount bonds within the CCAPM when bond prices are continuously marked-to-market for tax purposes. In the case of coupon bonds, however, tax effects will be absent only if the marginal investor's effective tax rate is zero [as, for example, in Miller and Scholes (1978)]. Also, Government bonds are not treated as net wealth here. One consequence is that they are not agoregated with the NYSE index to provide a wealth-surrogate for the CAPM. Some inter-generational models attribute non-neutral equilibrium effects to the issuance of bonds, though the existence of these effects often reouires restrictions on alternative modes of inter-generational transfer [see Samuelson (1958), Earro (1974), and Drazen (1978)].

Finally, the estimation and test procedures implemented here take cognizance of the issues raised by Roll (1979). Refore explaining, however, note that the methodology here is not that suggested by Roll (1979). Roll's (1979) reply to Mayers and Rice emphasizes that "the only relevant question is whether the CAPM is exactly linear (in beta)" (p.395) and that the 
alternative is a model with "an unspecified but nonconstant" intercept term. The tests here can be expressed in that form, but the methodology phrases the alternative partly in terms of the CAPM beta itself--the $B_{j I}$ in Rolls' terminology.

The central problem for CAPM tests raised by Roll (1979, p. 395) can be described as follows: In every sample, there will always exist portfolios that could serve as market index proxies guaranteeing that:

$$
E\left(R_{j}\right)=\gamma_{0}+\gamma_{l}^{B} j I \quad,
$$

where $E\left(R_{j}\right)$ is the expected rate of return on individual asset $j$ and $B_{j I}$ is its "risk" coefficient for a given index, I. In the same sample, there will always be proxies which guarantee that

$$
E\left(R_{j}\right)=\gamma_{0}+\gamma_{l}^{B} j I+\alpha_{j I},
$$

where $\alpha_{j I}$ is an unspecified but nonconstant vector [which is, incidentally, different for different choices of the index I].

Empirical tests of the CAPM thus face a dilemma. If $\alpha_{j I}=0$ and the CAPM is accepted, it may be that although the true market index is not efficient, the proxy is. In fact, the existence of mean-variance efficient proxies is guaranteed. On the other hand, if $\alpha_{j I} \neq 0$ and the CAPM is rejected, the opposite may have occurred, i.e., the proxy used in the test may be ex post inefficient, so that the test says nothing about the validity of the CAPM if the "true" market index is properly used. 
The preceding test of whether the CCAPM can be reduced to the SharpeLintner-Moss in CAPM is, in essence, just one test of the adequacy of changes in the NYSE index as surrogates for changes in investors' maroinal utilities. Explicit allowance is made for deviations of measured wealth from the true descriptor of marginal utility. Various proxies are treated as indicators of the marginal utility change variable; none are required to be individually the true marginal utility change.

The approach in no way contradicts Roll's central theme. The errorsin-the-variables model used here, complete with identification assumptions, is simply a sophisticated way of describing the difference between true marginal utility changes and their measured counterparts. The hypotheses tested are joint hypotheses of the validity of the errors-in-variables model and the asset pricing model ( 1 ). In fact, one of the most interestino ways to extend the test procedure here would be to deduce and impose further general restrictions on the measurement model specification--for example, it is economically sensible to restrict the percentage changes in investors' unobservable marginal utilities to be greater than minus one hundred percent. Such elaborations would permit a relaxation of some of the [nontestable] identifying assumptions in the measurement model. 
FOOTNOTES

* This paper is adapted from a section of my dissertation at the University of Chicago. I am grateful to Craig Ansley, Sudipto Bhattacharya, Douglas Rreeden, William Erock, Michael Gibbons, John P. Gould, Jerry Hausman, Jon Ingersoll, Allan Kleidon, Myron Scholes, Arnold Zellner; I am especially indebted to Merton Miller for his support and encouragement. Part of this paper was rewritten while I was a Batterymarch Fellow.

1 By way of comparison, the market value of NVSE listed stocks was about 1.3 trillion dollars.

2 I do not believe that the conditional expected return models are necessarily uninteresting, just that it must be realized that any extra information which they provide does not "come for free" (an obvious point which sometimes seems to get lost in discussion). Given what I believe are the priors of most researchers as to the extent of variation in real risk premiums on Government bonds, quite a strong prior would be needed for the conditional expected return-risk premium model before results could be considered as tests of anything other than the specification itself, especially when only about twenty years of data are available. If the conditional expected return-risk premium model were "rolled back" to a primitive expected utility maximization model, questions regarding its specification are likely to be an order of magnitude more important than variations in the real risk premiums.

3 If meaningful aggregation is not possible, uncertainty would be inherent in the distribution of wealth changes and price level changes, but an accounting for these is beyond the scope of this paper. In fact, the single price level index used here really makes sense only for homothetic preferences: "the fundamental and well-known theorem for the existence of a price index that is invariant under chanoe in level of living.... is that each dollar of income be spent in the same way by rich and poor, with income elasticities exactly unity (the homothetic case)." [Samuelson and Swamy (1974), p. 568].

4 As long as investors can hold diversified portfolios and maximize expected utility, there will always be a measure of systematic risk for a security which is defined in terms of the covariation of its returns with maroinal utilities [see Merton (1982, Section III) for discussion].

5 In the sociology/psychometric literature, (15) is called a path model. 
Robinson (1974) formulates the MIMIC model more cenerally, so that (14) might become:

$$
\begin{array}{ccc}
x_{1 t}=\gamma_{1} \xi_{t} & +\underline{\alpha}_{1} \underline{z}_{t} \\
\vdots & \vdots & \vdots \\
x_{k t} & =\gamma_{k} \dot{\xi}_{t}+\underline{\alpha}_{k} \underline{z}_{t} \\
\xi_{t}=\underline{\theta}^{\prime} & \underline{z}_{t}+u_{t}
\end{array}
$$

where $\underline{z}_{t}$ is a vector of causes of $\xi_{t}$ and $\underline{x}_{t}$. In this extended model, the interdependence between indicators and causes is even more complex, as are any propositions needed to justify labels on $x_{i}$ as indicators or causes.

7 It can be shown [Holly (1982)] that, against "local alternatives" [i.e., those for which the true covariance 012 converges to the null 0 at the rate $\checkmark T$ as the sample size $T$ increases], Hausman's test has the same asymptotic power as the conventional likelihood, LM and Wald procedures for testing whether $\sigma_{12}=0$. Note that since there are more nuisance parameters than the parameter of interest here $\left(\sigma_{12}\right)$, his result requires only correlation between $\sigma_{12}$ and those nuisance parameters.

8 MOMENTS was written by Bronwyn H. Hall (1979) and uses the Berndt, Hall, Hall, and Hausman (1977) scoring procedure.

9 This conclusion, like Bhattacharya's result and indeed the CCAPM ( 1 ) itself, is only rigorously true in the limit of continuous time. Some results in Gennotte and Marsh (1985) indirectly suggest that the extent of discrete-time approximation errors is trivial over monthly intervals, and Grauer's (1978) results imply that at least monthly stock returns are "sufficiently compact" that researchers are unable to apply models of relative asset prices to them and differentiate among power linear I isk tolerance utility functions.

10 The portfolios are similar in concept to those constructed and described by Bildersee $(1975,1978)$. Since bonds are "rolled across" portfolios as they approach maturity, the returns are not adjusted for taxes, and flower bonds are excluded. The average maturity of the bond portfolios and the total number of bonds in each are reasonably stable through time (more specific details are available upon request).

11 The likelihood ratio test, which will be a uniformly most powerful test if one exists, is asymptotically equivalent to the Lagrange Multiplier and wald tests. The "wald test" of coefficient equality in the Hausman exogeneity test uses the unrestricted regression coefficient estimates Iather than the restricted and unrestricted likelihood estimates. 


\section{REFERENCES}

Aigner, D.J., 1978, "Recent developments in econometric modelling with latent variables," Innublished manuscript, University of Southern California.

Barro, R.J., 1974, "Are government bonds net wealth?" Journal of Political Economy 82, 1095-1117.

Berndt, E.R., and N.E. Savin, 1977, "Conflict among criteria for testing hypotheses in the multivariate linear regression model," Econometrica $45,1263-77$.

Berndt, ․․, B.H. Hall, R.E. Ha11, and J.A. Hausman, 1974, "Estimation and inference in nonlinear structural models," Annals of Economic and Social Measurement 3, 653-665.

Ehattacharya, S., 1979, "A note on multi-period valuation and the pricing of options," Unpublished Draft, Graduate School of Business, University of chicago.

Bildersee, J.S., 1975, "Some new bond indexes," Journal of Eusiness 48, 506-25.

, 1978, "U.S. government and agency securities: An analys is of yield spreads and performance," Journal of Business 5l, 499-520.

Black, F., 1972, "Capital market equilibrium with restricted borrowing," Journal of Business 45, 444-454.

, M.C. Jensen, and M. Scholes, 1972, "The capital asset pricing model: Some empirical findings," in: M.C. Jensen, ed., Studies in the theory of capital markets (Praeger, New York), 79-121.

Breeden, D.T., 1979, "An intertemporal asset pricing model with stochastic consumption and investment opportunities," Journal of Financial Economics 7, 265-296.

, 1980, "Consumption risk in futures markets," Journal of Finance $35,503-520$.

, 1984, "Consumption, production, and interest rates: A synthesis," Forthcoming, Journal of Financial Economics.

Brock, W.A., 1982, "Asset prices in a production economy," in: J.J. McCall, ed., The Economics of Information and Uncertainty (University of Chicago Press, (hicago). 
Cox, J.C., J.E. Ingersoll, Jr., and S.A. Ross, 1977, "A theory of the term structure of interest rates and the valuation of interest-dependent claims," Unpublished manuscript, forthcoming: Econometrica.

Drazen, A., 1978, "Government debt, human capital, and bequests in a life-cycle model," Journal of Political Economy 86, 505-16.

Fama, E.F., 1975, "Short-term interest rates and inflation," American Economic Review 65, 269-282.

Fama, E.F., 1976, "Inflation uncertainty and expected returns on treasury bills," Journal of Political Economy 84, 427-48.

, 1977, "Interest rates and inflation: The message in the entrails," American Economic Review 67, 487-96.

, and J.D. Macbeth, 1973, "Risk, return, and equilibrium:

Empirical tests," Journal of Political Economy 81, 607-636.

Farebrother, R.W., 1980, "The Durbin-Watson test for serial correlation where there is no intercept in the regression," Econometrica 48, $1553-1563$.

Fisher, F.M., 1966, The identification problem in econometrics (McGraw- Hill Book Co., New York).

Fisher, I., 1930, The theory of interest (Reprinted by A.M. Kelly Publishers, New York, 1965).

Gennotte, G., and T.A. Marsh, 1985, "Variations in ex-ante risk premiums on capital assets," Working Paper, Sloan School of Management, MIT/E52-447, 50 Memorial Drive, Cambridge, MA 02139.

Gibbons, M.R., 1982, "Multivariate tests of financial models: A new approach," Journal of Financial Economics 10, 3-27.

, and $W$. Ferson, 1984, "Testing asset pricing models with

changing expectations and an unobservable market portfolio,"

Forthcoming, Journal of Financial Economics.

Goldberger, A.S., 1972a, "Structural eouation methods in the social sciences," Econometrica 40, 979-1001.

, 1972b, "Maximum likelihood estimation of regressions containing unobservable variables," in: D.J. Aigner and A.S. Goldberger, eds., Latent variables in socio-economic models (North-Holland, Amsterdam).

Grauer, R.R., 1978, "Generalized two parameter asset pricing models: Some empirical evidence," Journal of Financial Economics 6, 11-32. 
Grossman, S.J., and R.J. Shiller, 1982, "Consumption correlatedness and risk measurement in economies with nontraded assets and heterogeneous information," Journal of Financial Economics 10, 195-210. Hall, B.H., 1979, Moments: The moment matrix processor user's manual,
Version 1.1.

Hansen, L.P., and K.J. Singleton, 1982, "Generalized instrumental variables estimation of nonlinear rational expectations models," Econometrica 50 , $1269-1286$.

, 1983, "Stochastic consumption, risk aversion, and the temporal behavior of asset returns," Journal of Political Economy $91,249-265$.

Hausman, J.A., 1977, "Errors in variables in simultaneous equation models," Journal of Econometrics 5, 389-401.

46, 1251-71.

Hausman, J.A., and W.E. Taylor, 1981, "Identification in linear simultaneous equations models with covariance restrictions: An instrumental variables interpretation, "Working Paper 280, Department of Economics, MIT, 50 Memorial Drive, Cambridge, MA 02139 (April 1981).

Holly, A., 1982, "A remark on Hausman's specification test," Econometrica $50,749-759$.

Holly, A., and J.D. Sargan, 1981, "Testing for exogeneity within a limited information framework, "Unpublished manuscript, The London School of Economics.

Holly, A., and A. Monfort, 1982, "Some useful equivalance properties of Hausman's yest," Unpublished manuscript, Universite de Lausanne, Ecole des HEC, 1015 Lausanne-Dorigny, Switzerland.

Joreskog, K.G., and A.S. Goldberger, 1975, "Estimation of models with multiple indicators and multiple causes of a single latent variable," Journal of the American Statistical Association 70 (351) Part I, 631-39.

Lintner, J., 1965, "The valuation of risk assets and the selection of risky investments in stock portfolios and capital budgets," Review of Economics and Statistics 47, 13-37.

Lucas, R.E., Jr., 1975, "An equilibrium model of the business cycle," Journal of Political Economy 83, 1113-44.

Mankiw, N.G., and M.D. Shapiro, 1984, "Risk and return: Consumption versus market beta," National Eureau of Economic Research Working Paper \#1399, NBER, 1050 Massachusetts Avenue, Cambridge, MA 02138, (JuIy). 
Marsh, T.A., 1980, "Intertemporal capital asset pricing and the term structure of interest rates," Unpublished Ph.D. dissertation, Graduate School of Business, University of Chicago.

, 1984, "On Euler-equation restrictions on the temporal behavior of asset returns," Working paper \#1619-84, Sloan School of Management, MIT/E52-447, 50 Memorial Drive, Cambridge, MA 02139.

Merton, R.C., 1971, "Optimum consumption and portfolio rules in a continuous-time model," Journal of Economic Theory 3, 373-413.

, 1973, "An intertemporal capital asset pricing model," Econometrica $41,867-87$.

, 1980, "On estimating the expected return on the market," Journal of Financial Economics 8, 323-361.

, 1982, "On the mathematics and economic assumptions of continuous time models," in: W.F. Sharpe, ed., Financial economics: Essays in honor of Paul Cootner (North-Holland, Amsterdam).

Miller, M.H., and M.S. Scholes, 1978, "Dividends and taxes," Journal of Financial Economics 6, 333-64.

Mossin, J., 1966, "Equilibrium in a capital asset market," Econometrica 35, $768-783$.

Nakamura, A. and M. Nakamura, 1981, "On the relation among several specification error tests presented by Durbin, Wu, and Hausman," Econometrica 49, 1583-1587.

Robinson, P.M., 1974, "Identification, estimation and large-sample theory for regressions containing unobservable variables," International

Economic Review 15, 680-692. Reprinted in Latent variables in socioeconoic models, ed. by D.J. Aigner and A.S. Goldberger, (North-Holland Publishing Co, Amsterdam).

Roll, R., 1976, "A critique of the asset pricing theory's tests. Part I: On past and potential testability of the theory," Journal of Financial Economics 4, 129-76.

, 1979, "A reply to Mayers and Rice," Journal of Financial Economics 7, 391-400.

Ross, S.A., 1976, "The arbitrage theory of capital asset pricing," Journal of Economic Theory 13, 341-360.

, 1977, "Return, risk, and arbitrage," in: I. Friend and J.L. Bicksler, eds., Risk and return in finance, I (Eallinger, Cambridge, MA), $198-218$. 
Rothenberg, T.J., and C.T. Leenders, 1964, "Efficient estimation of simultaneous equation systems," Econometrica 32, 57-75.

Rubinstein, M., 1976, "The valuation of uncertain income streams and the pricing of options," Bell Journal of Economics 7, 407-425.

Samuelson, P.A., 1958, "An exact consumption loan model of interest with or without the social contrivance of money, "Journal of Political Economy, $66,467-482$.

Samuelson, P.A., and S. Swamy, 1974, "Invariant economic index numbers and canonical duality: Survey and synthesis," The American Economic Review, $64,566-593$.

Savin, N.E. and K.J. White, 1977, "The Durbin-Watson test for serial correlation with extreme sample sizes or many regressions," Econometrica; 45, 1989-1996.

Sharpe, W.F., 1964, "Capital asset prices: A theory of market equilibrium under conditions of risk," Journal of Finance 19, 425-42.

Tobin, J., 1958, "Liquidity preference as behavior towards risk," Review of Economic Studies 25, 65-85.

Zellner, A., 1970, "Estimation of regression relationships containing unobservable independent variables," International Economic Review II, 441-54. Reprinted in: D.J. Aigner and A.S. Goldberger, eds., Latent variables in socioeconomic models (North-Holland, Amsterdam). 
Estimates of the coefricjents of the "market model" equations for bond rates of return 1 over the period March 1959 to December 1980, computed using Hausman's instrumental variable procedure.

Bond

Portfolio

Maturity

0-6 mos.

6 mos -1 yr

1 уг -2 угs

2 yrs -3 yrs

3 yrs -5 yrs

> 5yrs

$$
\begin{gathered}
\text { MODEL: } R_{j t}^{j}=R_{12} R_{M a t}+R_{13}^{j} R_{F t}+\phi_{12}^{j} v_{t}+u_{j t} \\
R_{\text {Mat }}=\hat{q}^{\prime} \underline{z}_{t} \underline{2 l}
\end{gathered}
$$$$
v_{t}=R_{\text {Mat }}-\hat{R}_{\text {Mat }}
$$

$\hat{B}_{12}$

(std. Error)

${ }_{13}$

(std. Error)

$\phi 12$
0.023

$(0.011)$

0.065

$(0.029)$

0.112

$(0.049)$

0.123

$(0.072)$

0.079

$(0.095)$

0.049

(0.132)
1.103

$(0.016)$

1.121

$(0.043)$

1.074

(0.073)

1.045

$(0.107)$

0.960

(0.143)

0.963

$(0.199)$
(Std. Error)
$R^{2}$

$\begin{array}{lll}0.002 & 1.827 & 0.95\end{array}$

(0.001)

1.800

0.75

(0.004)

0.030

$(0.007)$

1.804

0.50

0.045

(0.011)

1.881

0.33

0.060

(0.014)

1.887

0.21

0.079

$(0.020)$

2.017

0.14

$1 /$ In the model, Rat, Pat, and Fit are respectively the real rates of return on security $j$, the market, and the risk-free asset in period $t$.

2) The indicator variables--percentage changes in seasonally adjusted retail sales of nondurable consumer goods, percentage changes in industrial production of nondurable consumer goods, the average realized real rate of return on one-month T-bills over the past twelve months, the growth rate of the monetary base over the past twelve months, and percentage changes in an interpolated monthly series of quarterly per capital consumption-are used, along with the predetermined nominal one month T-bill return and prior inflation rates, to form the vector $\underline{Z}$ in these regressions.

3/ With three regressors, the 0.05 significance level lower and upper limits for the Durbin-Watson statistics with 238 ohservations are 1.61 and 1.74 ; they are 1.738 and 1.799 in the extended tables of Savin and white (1977), and the lower limit is 1.728 in the Farebrother (1980) tabulations when there is no intercept in the regression as here. The corresponding values for the 0.01 significance level are $(1.48,1.60),(1.63,1.704)$, and 1.634 . 
lable 2

FIML estimates of the coefficients of the "market model"

equations for bond rates of return $1 /$ over the period March 1959 to December 1980, computed using the MOMENTS program.

MODEL :

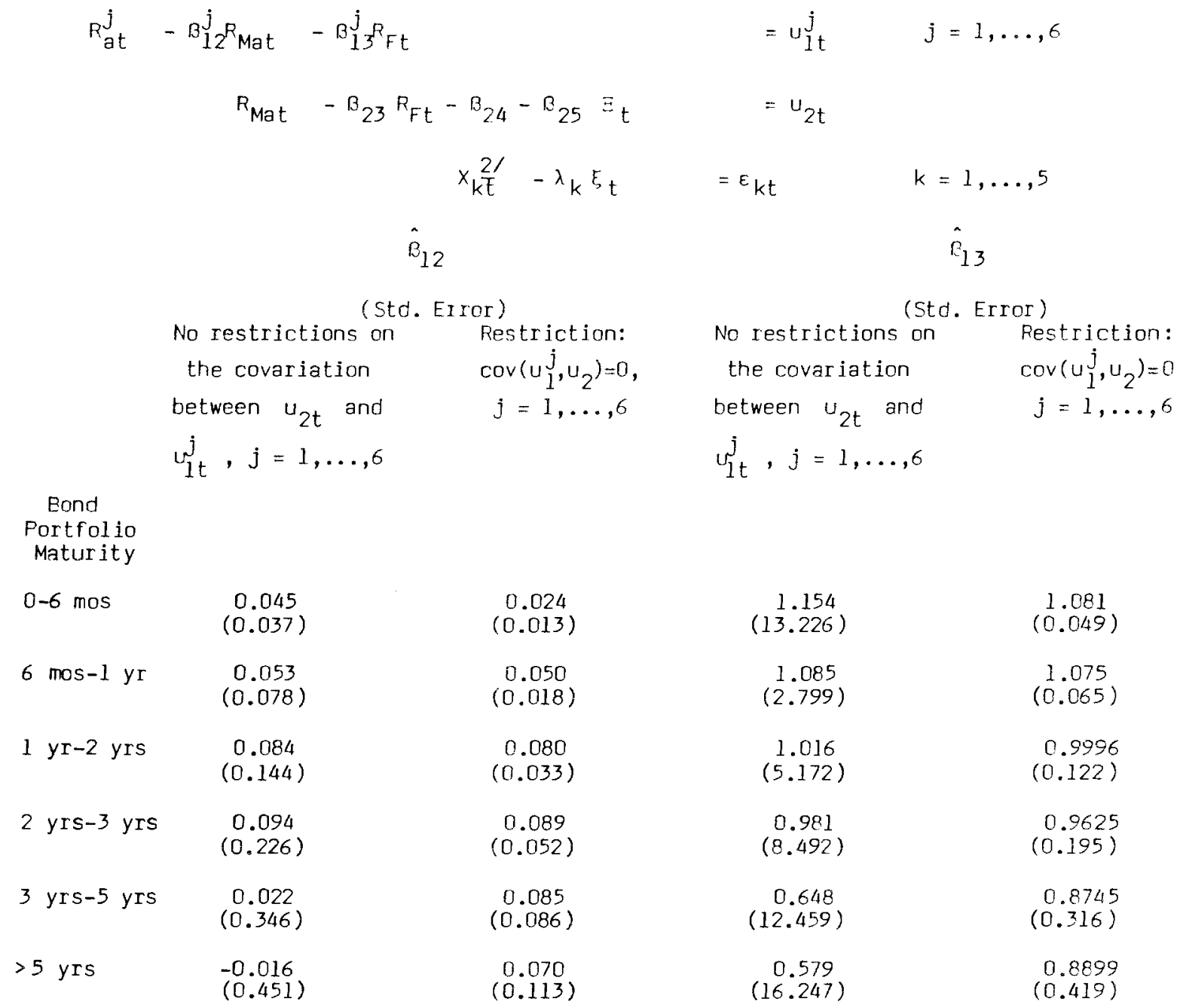

1/ In the model, Rjt, RMat, and $R_{F t}$ are respectively the real rates of return on' security $\mathrm{J}$, the market, and the risk-free asset in period $t$.

2/ The indicator variables--percentage changes in seasonally adjusted in retaj sales of nondurable consumer goods, percentage changes in industrial production of nondurable consumer goods, the average realized real rate of return on one-month T-bills over the past twelve months, the growth rate of the monetary base over the past twelve months, and percentage changes in an interpolated monthly series of quarterly per capital consumption--are used, along with the predetermined nominal one month $T-b i l l$ return and prior inflation rates, to form the vector $\underline{Z}$ in these regressions. 
Table 3

Tests of asset pricing model specificationl/ applied to rates of return on long-term Government bonds over the period March 1959 to December 1978 .

$$
\begin{array}{lcc} 
& \text { Hausman } & \text { FIML } \\
\text { Bond Maturity } & \text { Procedure } & \text { MOMENTS }
\end{array}
$$

Hypothesis H' (where applicable) $^{2 /} \quad \infty^{2}$ or F stat. p-value $\infty^{2}$ or F stat. p-value

$\begin{array}{llr} & 0-6 \text { mos } & 18.224 \\ 6 \text { mos-1 yr } & 3.400 \\ 1 \text { yr-2 yrs } & 0.051 \\ 2 \text { yrs }-3 \text { yrs } & 0.042 \\ 3 \text { yrs-5 yrs } & 0.092 \\ >5 \text { yrs } & 0.047\end{array}$

$\begin{array}{lllll}2 & 14.31 & 0.025 & 341.44 & <0.005\end{array}$

3

$14.46 \quad 0.025 \quad 1074.15$

$\begin{array}{llrll}0-6 \text { mos } & 17.890 & & \\ 6 \text { mos-1 yr } & 3.385 & & \\ 1 \text { yr-2 yrs } & 0.047 & 0.000 & 1.000 \\ 2 \text { yrs }-3 \text { yrs } & 0.038 & & \\ 3 \text { yrs }-5 \text { yrs } & 0.044 & & \\ >5 \text { yrs } & 0.049 & & \end{array}$

I'The hypotheses tested are:

$H_{0}(1)$ : The CCAPM holds for pricing default-free bonds;

$H_{0}(2)$ : The CCAPM does not add incremental explanatory power to the CAPM;

$\mathrm{H}_{\mathrm{O}}(3)$ : Per capita consumption changes do not reflect changes in investors' marginal utilities any better than do returns on the NYSE value-weighted index when the pricing of bonds isn't constrained to conform with the CCAPM;

$\mathrm{H}_{0}(4)$ : The Sharpe-Lintner-Mossin CAPM holds.

$\underline{2} H_{0}(1)$ and $H_{0}(4)$ are each tested for each bond maturity separately using instrumental variables, and for all bond maturities jointly using FIML. $\mathrm{H}_{0}(2)$ and $\mathrm{H}_{0}(3)$ are tested for all bond maturities jointly using Hausman's exogeneity test and FIML. 